\title{
(1) castana \\ Resolved heart tamponade and controlled exophthalmos, facial pain and diabetes insipidus due to Erdheim-Chester disease
}

\author{
Jaume Monmany, ${ }^{1}$ Esther Granell, ${ }^{2}$ Laura López, ${ }^{3}$ Pere Domingo ${ }^{1}$
}

${ }^{1}$ Medicina Interna, Hospital de la Santa Creu i Sant Pau, Barcelona, Spain

${ }^{2}$ Diagnòstic per la Imatge, Hospital de la Santa Creu i Sant Pau, Barcelona, Spain

${ }^{3}$ Anatomia Patològica, Hospital de la Santa Creu i Sant Pau, Barcelona, Spain

\section{Correspondence to} Dr Jaume Monmany, jmonmanyr@monmany.net

Accepted 1 October 2018
Check for updates

(c) BMJ Publishing Group Limited 2018. Re-use permitted under CC BY-NC. No commercial re-use. See rights and permissions. Published by BMJ.

To cite: Monmany J, Granell E, López L, et al. BMJ Case Rep Published Online First: [please include Day Month Year]. doi:10.1136/ bcr-2018-225224

\section{SUMMARY}

A 69-year-old woman suffering from exophthalmos and facial pain came to us referred for aetiological diagnosis of exophthalmos. Orbital MRI showed thinned extrinsic ocular musculature, intraconal fat infiltration, retro-ocular compression and thickening of maxillary and sphenoid sinus walls. She had been suffering from diabetes insipidus for the last 7 years. During our diagnosis process, she presented signs of cardiac tamponade. Transthoracic heart ultrasound revealed large pericardial effusion and a heterogeneous mass that compressed the right ventricle. No osteosclerotic lesions on appendicular bones were present. Pericardiocentesis temporarily controlled tamponade and corticoid therapy temporarily abated exophthalmos. Pericardiectomy definitively resolved tamponade. Histological examination of pericardial tissue was conclusive of Erdheim-Chester disease. Exophthalmos responded to pegylated interferon-alpha-2a. Facial bone pain disappeared after zoledronic acid and interferon treatment. During interferon therapy, the patient suffered from a severe generalised desquamative exanthema that slowly resolved after discontinuing interferon. Diabetes insipidus remains controlled with desmopressin.

\section{BACKGROUND}

Rare and dangerous Erdheim-Chester disease (ECD) is a histiocytosis, histologically characterised by xanthomatous infiltrate by histiocytes that show CD68 but not CD1a markers. ${ }^{1-5}$ It may affect any organ, but especially bones, heart, great vessels, neurohypophysis, orbits, eyes, cerebellum, retroperitoneal space and lungs. ${ }^{2-5}$ It predominantly affects adult men. ${ }^{125}$ William Chester and Jakob Erdheim published the first case in 1930 as a lipoid granulomatosis. ${ }^{256}$ Seven hundred and fifty cases have been reported to date, ${ }^{27}$ most of them in the last 15 years. ${ }^{2}$ The first case in PubMed is dated $1978 .^{8}$ The first report about ophthalmological manifestations appeared in $1983 . .^{9}$ Despite the fact that ECD has no cure $^{3-5}$ and that historically the prognosis has been bad, especially in patients with central nervous system involvement, ${ }^{310}$ prognosis improved when interferon alpha was introduced into its treatment in $2001,,^{310-13}$ based on a previous experience in Langerhans cell histiocytosis (LCH). ${ }^{14}$ More therapeutic and understanding progress has been made since 2012, when a case was reported of ECD that presented the V600E mutation of the BRAF gene, ${ }^{15}$ which is involved in cell proliferation through the mitogen-activated protein kinase (MAPK) cell signalling system from cell surface to DNA in nucleus. ${ }^{16}$ This mutation had previously shown to be present in more than $50 \%$ of $\mathrm{LCH}$ cases $^{17}$ and later in almost $50 \%$ of cases of ECD, ${ }^{2}{ }^{18-20}$ which has allowed ECD, ${ }^{2} 721-26$ and also $\mathrm{LCH},{ }^{27}{ }^{28}$ to be treated with BRAF gene inhibitors. The discovery of other mutations in MAPK 2029 and in other cell signalling systems, ${ }^{20}$ and the fact that many patients who do not present V600E BRAF do present these other mutations, ${ }^{2} 2030-34$ confer more possibilities of treatment with gen inhibitors, ${ }^{2} 2935$ which has supposed better outcomes in survival analysis. ${ }^{2}$ Real-time genomic profiling of histiocytes should allow these new treatments to be given without delay. ${ }^{36}$ Despite these treatment advances, there is not yet a fully standardised treatment of ECD. A consensus guideline was published in $2014,{ }^{37}$ which has not been updated since. In general, interferon alpha is considered to be the first-line treatment. In the case of disease progression despite interferon therapy, a clinical trial with a BRAF inhibitor for BRAF-positive patients is indicated and, for those BRAF negative, either an antineoplastic (anakinra, imatinib, cladribine or cyclophosphamide) $37-40$ or a clinical trial with the newer gene inhibitors is indicated. Bone marrow transplantation has been resorted to in some cases. ${ }^{4142}$

ECD is clinically and biologically similar to $\mathrm{LCH}$ except that histiocytes in $\mathrm{LCH}$ are CD1a positive, ${ }^{2}$ which is the reason why ECD has classically been defined as a non-Langerhans histiocytosis ${ }^{3-5}$; however, since 2016, it has been included in the Langerhans group of histiocytosis. ${ }^{1}$ Other groups of histiocytosis are: cutaneous and mucocutaneous histiocytosis, Rosai-Dorfman disease, malignant histiocytosis and haemophagocytic lymphohistiocytosis and macrophage activation syndrome. By this classification, based on histological, molecular, clinical and image criteria, more than 100 subtypes of histiocytoses have been grouped in five groups. ${ }^{1}$ There has been disquisition about if histiocytoses represent an inflammatory disorder or a neoplasia. ${ }^{24-45}$ The oncogenic mutations found in a high percentages of $\mathrm{LCH}$ and ECD cases confer a clonal character to these diseases. ${ }^{2}$ There is some ontogenic evidence that histiocytes of $\mathrm{LCH}$ and ECD might come from bone-marrow precursors. ${ }^{2}$ In consequence, ECD and $\mathrm{LCH}$ are considered now 


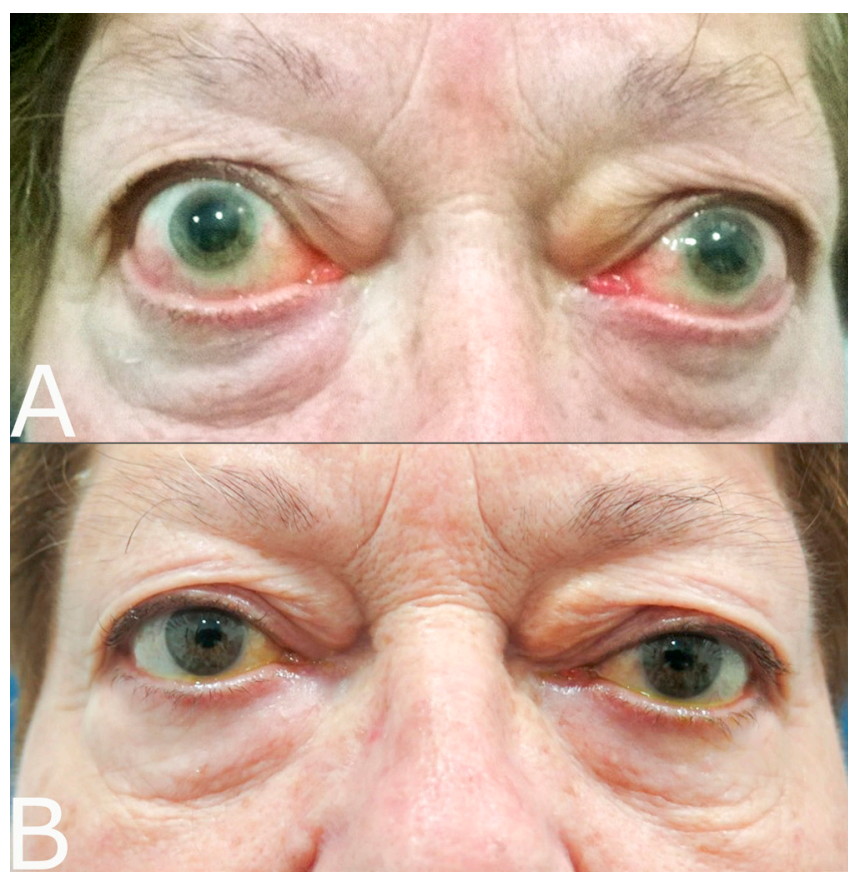

Figure 1 (A) Proptosis and red and redundant conjunctiva (conjunctivochalasis), before treatment with interferon and corticoids. Pupils are dilated with epinephrine for fundus examination. (B) Remission of proptosis, conjunctiva inflammation and conjunctivochalasis after treatment with interferon and corticoids.

by many as a myeloid neoplasia, ${ }^{243}$ although inflammation is a prominent manifestation. ${ }^{2}$

The present case is relevant because it proves that tamponade, a severe ECD heart complication, may be overcome by pericardiectomy, a different method to that normally undertaken; it discloses that lacking appendicular bone involvement, a clinical aspect considered as universal in $\mathrm{ECD},{ }^{3-5}$ does not rule it out; it exemplifies that interferon, the most recognised treatment for ECD, may be difficult to apply because of a challenging skin reaction that we describe; it points out a particularity in orbital imaging of ECD exophthalmos that helps in differential diagnosis; and it contributes to the knowledge of a rare and not yet fully characterised disease.

\section{CASE PRESENTATION}

A 69-year-old Caucasian woman came to the internal medicine outpatient service referred for aetiological diagnosis of exophthalmos that had appeared 6 months earlier. She had been complaining of itching, eye dropping and conjunctival irritation. More recently, she had noticed eye protrusion (figure 1A). She also complained of facial pain in maxillary region. She had been diagnosed as having diabetes insipidus 7 years earlier and has been treated with desmopressin since then.

Orbital MRI showed intraconal fat tissue occupation and infiltration (figures 2A, B, 3A, B and C) that embraced the extrinsic ocular musculature (figures 2 and 3), which looked thinned and compressed (figures 2A,B and 3C) and caused retroocular compression and important bilateral exophthalmos (figure 2C). There was also wall thickening of sphenoid and of both maxillary sinuses (figures $2 \mathrm{~B}$ and $3 \mathrm{~B}, \mathrm{C}$ ). The sella turcica was small, the posterior pituitary lobe was absent and the anterior one was normal (figure 4).

Ophthalmological examination (figure 1A) showed proptosis, limitation of all eye movements, red conjunctiva, conjunctivochalasis (redundant conjunctiva), superficial punctate keratopathy in biomicroscopy on left eye, inferior eyelid retraction, normal visual acuity in right eye and nearly normal in the left eye, increased intraocular pressure in right eye and epiphora in left eye with nasolacrimal duct obstruction evidenced by probing. There was not diplopia or lagophthalmos.

A full anterior hypophyseal hormonal evaluation was normal.

Two months later, she presented dyspnoea, orthopnoea and dry cough, the latter especially in decubitus position. We noticed prominent jugular ingurgitation, arterial pulse decrease on inspiration and low cardiac tones. A Doppler echocardiogram confirmed cardiac tamponade. The patient clearly improved after pericardiocentesis. The exophthalmos improved after treatment with intravenous methylprednisolone pulses followed by oral prednisone.

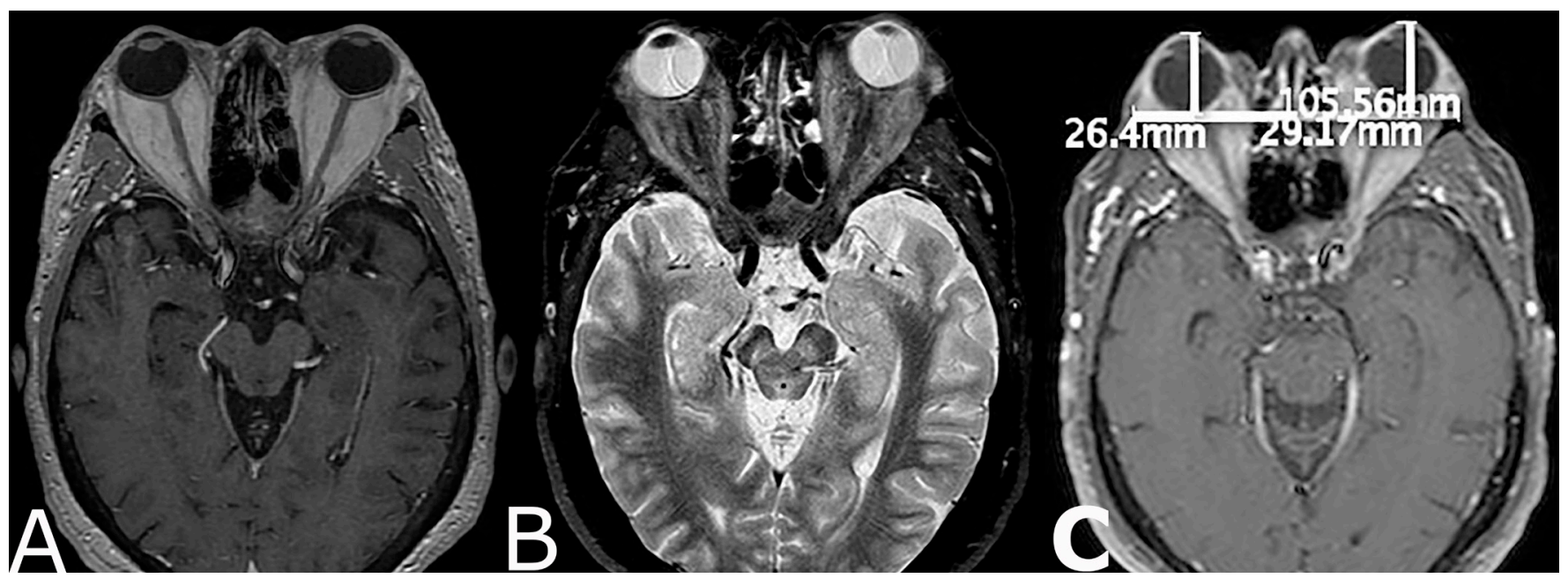

Figure 2 Severe bilateral proptosis due to retroocular compression because of intraconal fat infiltration that embraced extrinsic ocular musculature, which looks thinned and compressed, on orbital MRI with gadolinium (MRI), axial T1 view, before treatment with interferon and corticoids (A), plus sphenoid bone hypointensity suggesting osteosclerosis and mucous thickening within the sinuses on axial short-TI inversion recovery MRI (B), before interferon alpha treatment. Figure part $\mathrm{C}$ shows severe measured proptosis in axial T1 orbital axial MRI with gadolinium before treatment with interferon alpha. 


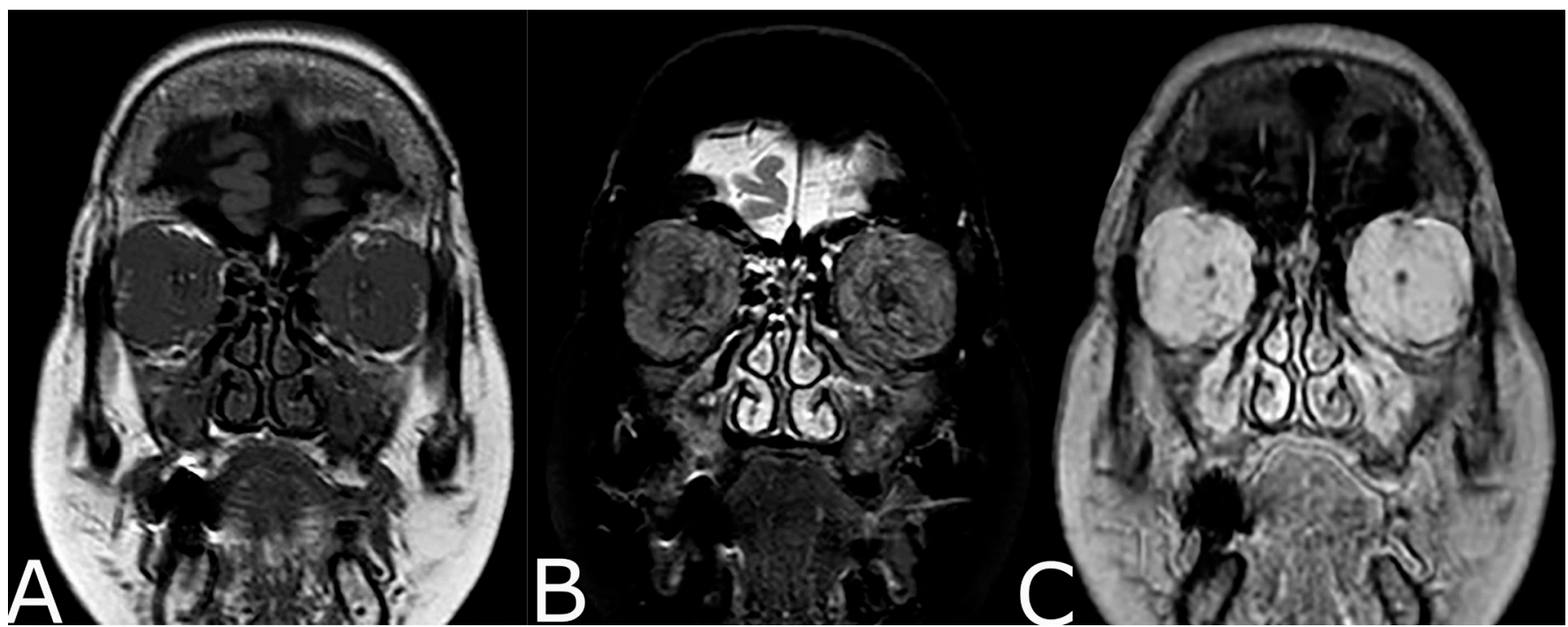

Figure 3 Severe intraconal fat tissue infiltration on a coronal T1 orbital MRI (A), plus maxillary infiltration on coronal STIR MRI (B), before interferon alpha treatment. Extrinsic ocular musculature looks thinned embraced by severe intraconal fat tissue infiltration, and there is maxillary bone and mucous thickening on T1 coronal orbital MRI with gadolinium (C), before interferon alpha treatment.

However, both exophthalmos and tamponade came back soon, more severe and menacing. Transthoracic echocardiography showed a heterogeneous mass, $3 \mathrm{~cm}$ by $2.5 \mathrm{~cm}$, next to the right coronary sulcus, which could compress the right ventricle (figure 5) in addition to pericardial effusion. We decided that pericardiectomy should be performed to resolve tamponade. Cardiac surgeons found a yellow tissue mass that infiltrated cardiac fat. This lesion reminded them of ECD, based on previous experience. ${ }^{3-5}$ Histological examination of pericardial tissue showed fibrotic chronic inflammatory infiltrate (figure 6) composed of lymphocytes and cumulus of foamy CD68 positive/ CD1a negative histiocytes (figure 7). Based on this information and on clinical data, we considered that the patient suffered from ECD. ${ }^{3-5}$ Deoxyribonucleic direct sequencing for BRAF gene, requested for therapeutic purposes, was negative.

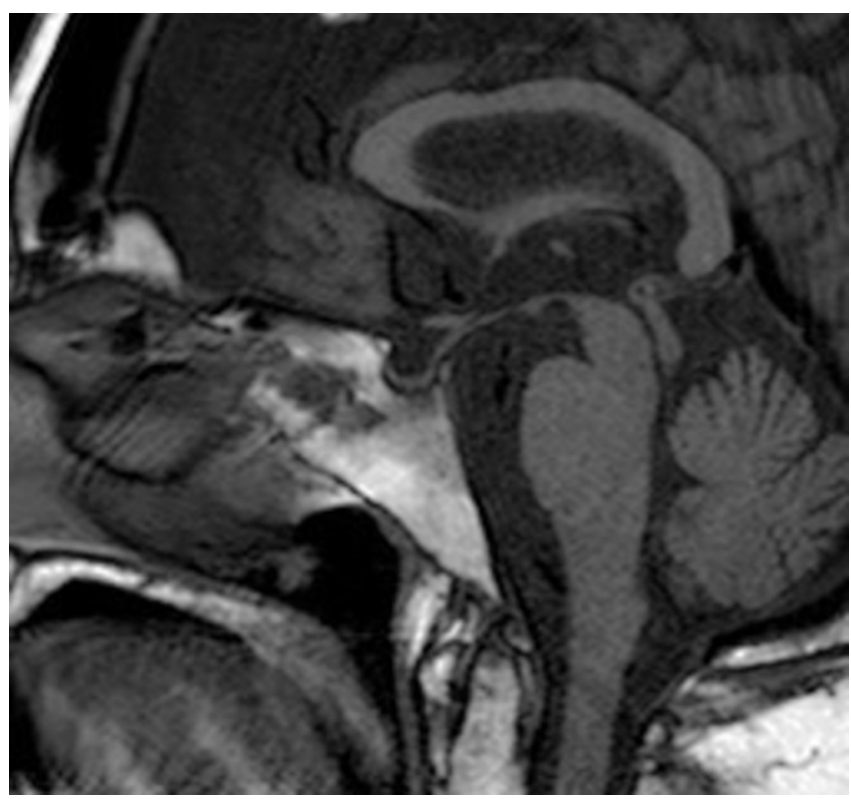

Figure 4 Absence of the posterior pituitary T1 bright spot concordant with diabetes insipidus, normal anterior pituitary lobe, small sella turcica and wall thickening of sphenoid sinus in a sagittal T1 MRI.
At that moment, our patient did not complain of appendicular bone pain, and we did not find suggestive osteosclerotic lesions on appendicular bones on either simple X-ray or Fludeoxyglucose (18F) Positron Emission Tomography-Computed Tomography (18F-FDG PET-CT), which did not include the arms and the legs beyond the distal portion of the femurs, or on technetium Tc $99 \mathrm{~m}$ hydroxydiphosphonate (99mTc-HDP) bone scan, the second performed later, once the patient was under treatment with corticoids and interferon alpha, all of them considered highly characteristic of ECD ${ }^{3-5} 46$ 99mTc-HDP more sensitive than 18F-FDG PET-CT for this purpose. ${ }^{47} 18 \mathrm{~F}-\mathrm{FDG}$ PET-CT neither evidenced aortic inflammation, which is also frequent in $\mathrm{ECD},{ }^{3-5}$ nor did the hairy kidney pattern, a frequent and very specific sign on abdominal CT. ${ }^{48-50}$ However, $18 \mathrm{~F}-\mathrm{FDG}$ PET-CT did show diffuse increased metabolism of extrinsic ocular musculature, retroocular soft tissue increased density with normal metabolism (figure 8) and pericardial effusion with normal metabolism.

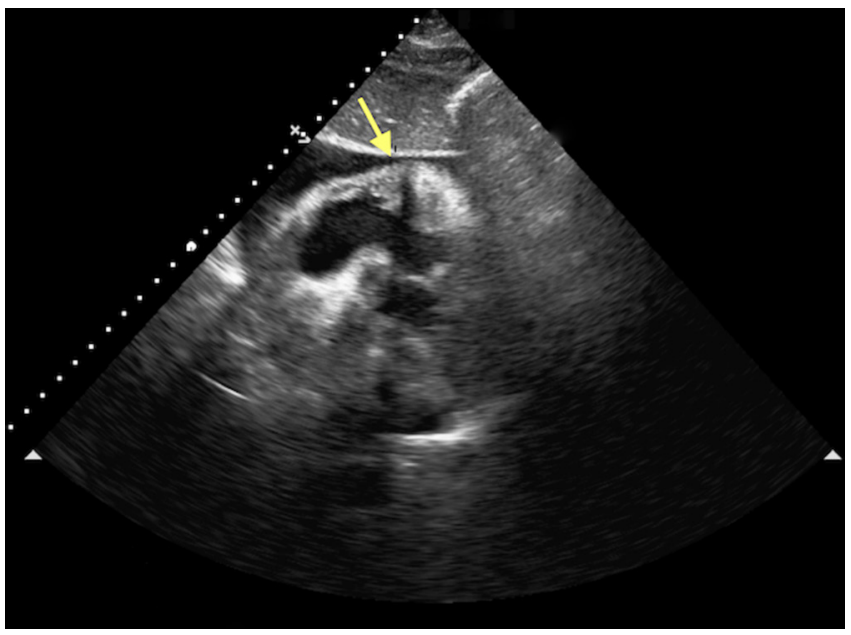

Figure 5 Heterogeneous mass, $3 \mathrm{~cm}$ by $2.5 \mathrm{~cm}$, yellow arrow, next to the right coronary sulcus, which could compress the right ventricle, in transthoracic echocardiography. 


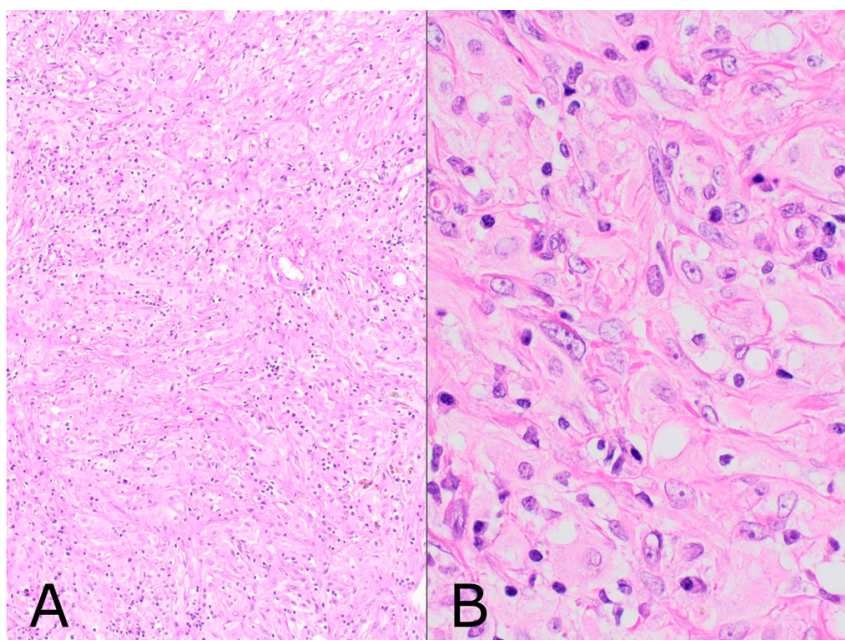

Figure 6 The pericardial tissue histological examination shows fibrotic tissue and diffuse mononuclear infiltration of histiocytes and small lymphoid aggregates (A: H\&E stain at 100x). The histiocytes show a large pale staining and foamy cytoplasm (B: H\&E stain at $400 \times$ ).

\section{DIFFERENTIAL DIAGNOSIS}

Bilateral exophthalmos (figure 1) and retro-orbital MRI (figures 2 and 3) made us think of several entities. ECD ophthalmopathy is similar to Graves' ophthalmopathy $(\mathrm{GO})^{51}{ }^{52}$; however, extrinsic ocular muscles look enlarged and orbital fat is not infiltrated in GO radiological imaging, ${ }^{53} 54$ while the first looked thinned and compressed and the later infiltrated in our patient, in whom antithyrotropin antibodies were negative, while they are positive in $97 \%$ of patients suffering severe $\mathrm{GO},{ }^{55}$ as well as thyroid function has remained normal in her, while there is hyperthyroidism in $90 \%$ of patients suffering GO. ${ }^{53}$ Retro-orbital lymphoma ${ }^{56-58}$ and granulomatosis with poliangiitis (GPA $)^{59-61}$ may present as our patient did. As in our patient, paranasal sinuses are frequently involved in GPA radiological images, which also show bone erosion ${ }^{62}$ that was not present in our case. Furthermore, antineutrophil cytoplasmic antibody were negative in our patient while they are positive in 4 of 5 patients with active GPA disease. ${ }^{63}$ Anterior uveitis is the most common manifestation of orbital sarcoidosis (OS), ${ }^{64}$ but OS may be present without uveitis, even without systemic disease, ${ }^{65}$ so it could

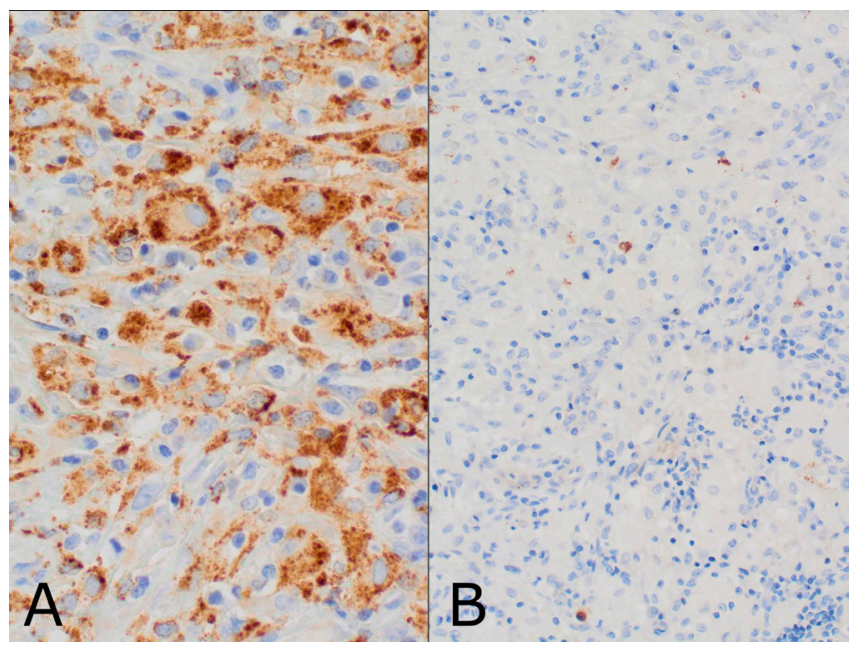

Figure 7 The immunohistochemical stain was positive for CD68 (A) and negative (no reaction) for CD1a (B).

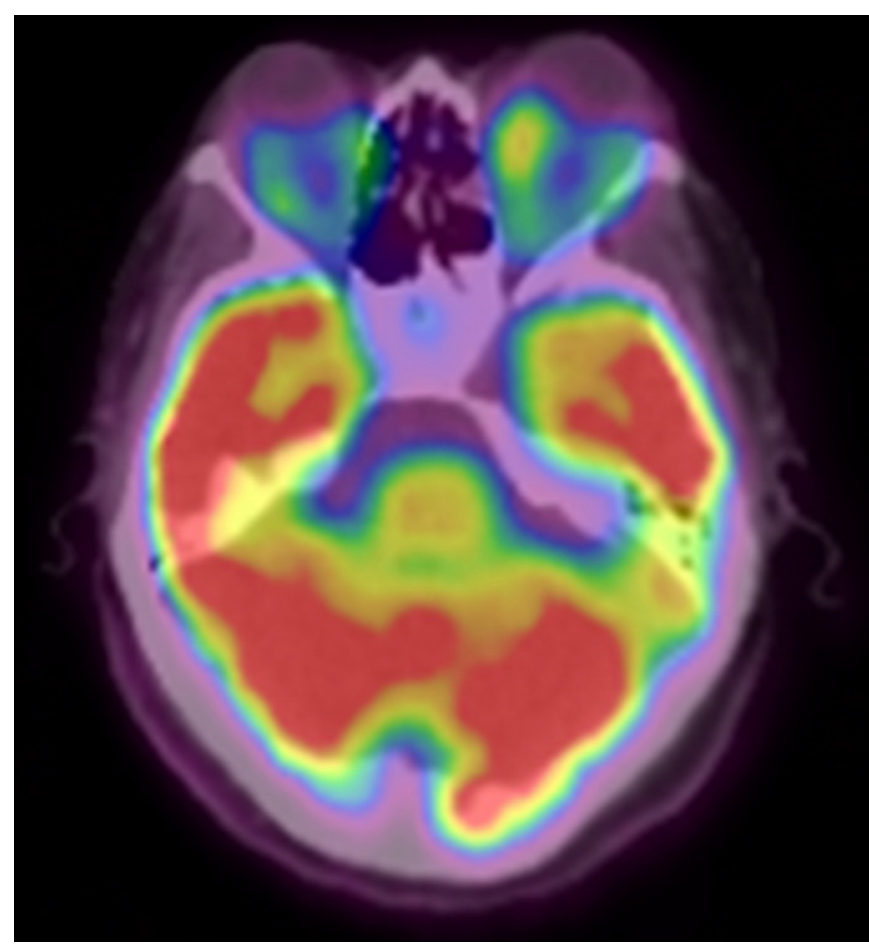

Figure 8 Diffuse increased metabolism of extrinsic ocular muscularity and retro-ocular soft tissue increased density with normal metabolism in 18F-FDG PET-CT before treatment with interferon alpha and corticoids.

resemble our case; however, OS usually clinically manifests as a palpable mass or as eyelid swelling, different from our patient who presented diffuse severe exophthalmos, and radiologically lacrimal gland infiltration, optic nerve sheath, dural infiltrations are frequent OS manifestations, ${ }^{6566}$ which were not present in our patient. Idiopathic orbital inflammation would clinically and radiologically reassemble our case ${ }^{67-70}$ except for the fact that it is usually unilateral and acute, ${ }^{67} 68$ that making a strong difference. Immunoglobulin G4-related ophthalmic disease could also resemble our case, ${ }^{71}$ but it typically involves lacrimal gland, ${ }^{71}$ trigeminal branch and extraocular muscles, which appear enlarged ${ }^{72}$; all of these were not present in our patient. Uncommon orbital metastases, ${ }^{73-75}$ sometimes without primary malignancy, ${ }^{73}$ sometimes bilateral ${ }^{73}$ and sometimes manifested as enophthalmos, ${ }^{70}$ except for the latter, could present in a similar way to our patient; however, MR or CT patterns of orbital metastases may have some specificity, ${ }^{7377}$ but not always. Tolosa-Hunt syndrome, ${ }^{78}$ orbital rhabdomyosarcoma ${ }^{79} 80$ and postseptal cellulitis, ${ }^{81-83}$ because of unilaterality, rapid instauration or characteristic radiological images were not considered.

Orbital biopsy, usually a fine-needle aspiration biopsy, sometimes an open biopsy ${ }^{58}$ or, more convenient, a sutureless aspiration cutter biopsy ${ }^{84}$ is normally necessary to achieve a diagnosis in these settings. ${ }^{56-586165677385}$ The Ophthalmology service postponed performing a biopsy until having more results. Then the patient suffered the pericardial complications that conduced to the pericardiectomy that proportionated the tissue for histological diagnosis.

\section{TREATMENT}

Pericardiectomy definitively resolved the cardiac problems, but severe exophthalmos remained. As interferon is the most widely proposed first drug in ECD treatment and as it is associated with increased survival, ${ }^{3-5} 10$ we prescribed pegylated 


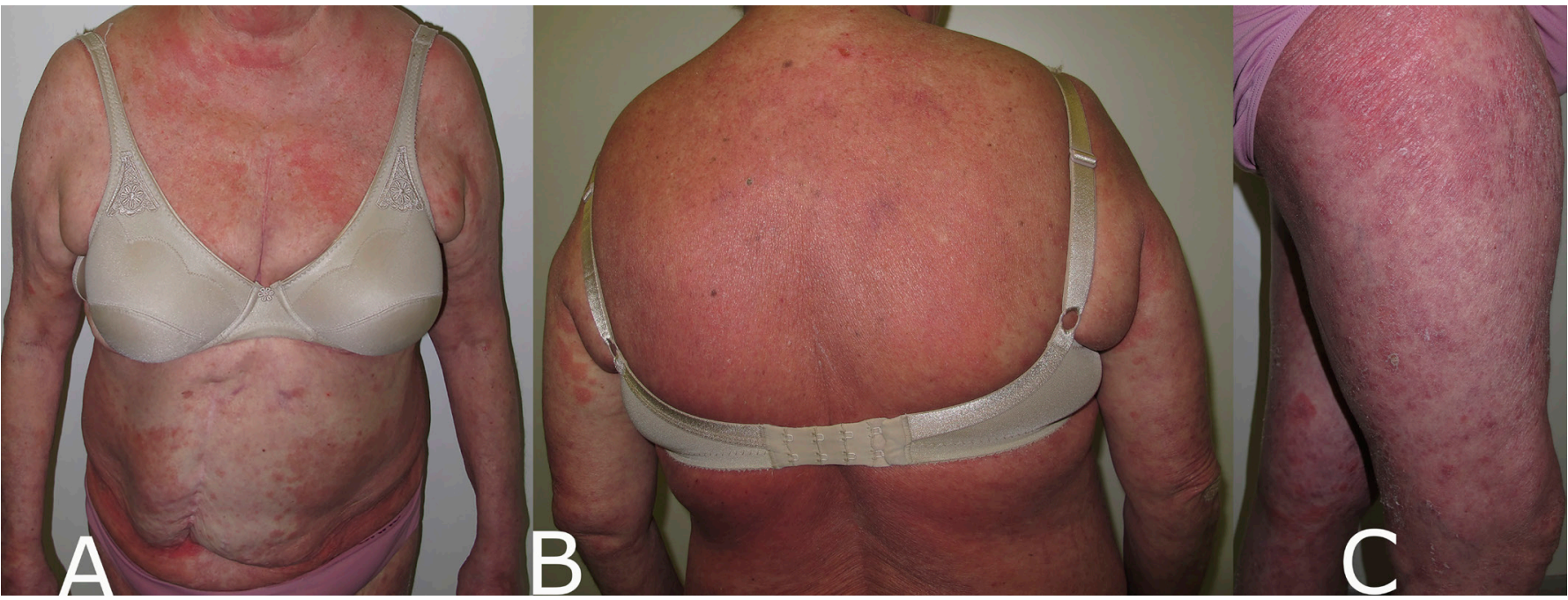

Figure 9 Generalised erythematous scaly plaques on the trunk, abdomen and extremities, which appeared during pegylated interferon-alpha-2a.

interferon-alpha-2a, Pegasys, at $135 \mu \mathrm{g}$ per week, by subcutaneous route, together with methylprednisolone pulses by intravenous route, $500 \mathrm{mg}$ per week for 6 weeks, then $250 \mathrm{mg}$ per week for a further 6 weeks, with a total of $4.5 \mathrm{~g}$. We prescribed zoledronic acid in order to prevent osteoporosis induced by corticoids. The exophthalmos progressively improved to almost normalisation (figure 1B). Facial bone pain disappeared, and wall thickening of sphenoid and maxillary sinuses improved.

\section{OUTCOME AND FOLLOW-UP}

After receiving the ninth dose of interferon, the patient suffered from a generalised exanthema with itching and desquamative macular skin lesions on the arms, thorax, dorsa, abdomen and legs: everywhere except for the face (figure 9). Examination of a punch cutaneous biopsy was indicative of a lichenoid drug eruption. Oral prednisone, topical triamcinolone and oral hydroxyzine provided some benefit. As we considered interferon therapy to be necessary, we kept prescribing it. The next three interferon administrations were somewhat better tolerated; however, after the fourth administration, the generalised exanthema became severely exacerbated and unbearable. At that time, the exophthalmos had remitted. Considering both the adverse skin reaction and the exophthalmos remission, we stopped interferon. The patient had received 15 doses in total. The generalised desquamative exanthema improved to complete remission in 4 weeks. Diabetes insipidus did not show any modification, either improvement or worsening, throughout the process with us. The exophthalmos has kept in remission despite interferon alpha suppression and despite no more corticoid administration.

\section{DISCUSSION}

It was a challenging process to obtain the diagnosis in our patient, because it was elusive, the disease was rare and severe and because it encompassed a considerable delay. Such difficulties are not unusual in ECD. Initially, when our patient presented exophthalmos and long-lasting diabetes insipidus but not yet heart disease, we did not suspect ECD, despite the fact that the association of exophthalmos and diabetes insipidus poses a strong suspicion of such disease..$^{3-5}{ }^{13-91}$ It was not until she presented heart tamponade that we considered a histiocytosis as a possible cause. However, the fact that we did not find appendicular bone involvement, reported as nearly always being present in histiocytosis, including ECD, ${ }^{5879092-103}$ made us think of histiocytosis as a remote aetiology. Despite the fact that some cases of delayed ${ }^{104}$ or lacking ${ }^{105}$ bone involvement have been described, absence of bone involvement has meant that ECD was only diagnosed postmortem in some patients. ${ }^{106}$ Consequently, ECD should not be ruled out because of the absence of appendicular bone involvement. Our patient had painful facial bone involvement (figures $2 \mathrm{~B}$ and $3 \mathrm{~B}, \mathrm{C}$ ), which is frequent in ECD. ${ }^{107-115}$ What is infrequent is to find axial bone involvement without appendicular bone involvement, ${ }^{107} 116$ as in our case. Perhaps if we had requested $99 \mathrm{mTc}-\mathrm{HDP}$ bone scan previously to the interferon and corticoid treatment or if 18F-FDG PET-CT had included the whole extremities, we would have detected it. We prescribed zoledronic acid to prevent steroid-induced osteoporosis and interferon to treat exophthalmos. Zoledronic acid, alone $^{117118}$ or combined with interferon alpha, ${ }^{98} 116$ has been reported to be very useful to treat axial ECD bone involvement, as it was in our patient.

Diabetes insipidus is a frequent manifestation of $\mathrm{ECD}^{119}$ that either precedes ${ }^{89} 108$ 119-130 or sometimes coincides ${ }^{131-134}$ with other manifestations of the disease but rarely follows them. ${ }^{135} 136$ This sequence of events frequently causes a delay in establishing ECD as the cause of diabetes insipidus, 5119129131136137 as occurred in our case. However, diabetes insipidus onset in an adult should arouse suspicion of an extracranial disease involving the pituitary stalk. Among them histiocytoses are prominent and can be detected early by means of 18 F-FDG PET-CT ${ }^{122}$ or brain MRI with gadolinium. ${ }^{87138}$ This is important because ECD-associated diabetes insipidus only responds to ECD therapy when administered soon after diabetes insipidus onset ${ }^{98130}$; if treatment for ECD is delayed, which frequently occurres, ${ }^{139}$ as in our case, it does not resolve diabetes insipidus. Our patient did not present any anterior hypophyseal hormonal disorder, which has been reported as very frequent in ECD when looked for. ${ }^{119}$

Patient's exophthalmos characteristics were in concordance with what is described in ECD. ${ }^{51}{ }^{140}$ Fortunately, she did not suffer blindness, which is frequently reported in ECD. ${ }^{51} 140$ Orbital MRI of the patient (figures 2 and 3) were also in line with what is commonly reported, ${ }^{51} 140$ including thinned and compressed extrinsic ocular musculature (figures $2 \mathrm{~A}$ and 3C). ${ }^{52141}$ The latter may be useful to distinguish between exophthalmos caused by ECD and that caused by Graves' disease, 
Patient's perspective

This morning the doctor asked me to write a summary of the process of my disease, basically how I have felt physically and mentally. I feel unhappy to have to recall everything about my disease, but I want to express my gratitude to the doctors who have taken care of me, because of their medical and psychological help. I want to contribute as much as I can to research into my disease.

We are in the summer of 2015, in the house by the beach and I feel quite well. I have had to overcome the death of my granddaughter.

Near the end of the summer I began to notice discomfort in my eye, so I went to my ophthalmologist, and she prescribed eye drops for me and told me to come back in a few days. This was repeated for three times, my discomfort became worse, so the ophthalmologist ordered a cranial magnetic resonance to be performed on me. When I heard the radiologist comment that he was surprised that this test was requested by an ophthalmologist, I became very worried.

With the results, at the beginning of January 2016, that said that I had bilateral exophthalmos, more on the left side than on the right, I went back to the ophthalmologist who, when she saw the results, called another doctor to have her opinion about this result. They told us that there was a tumour behind my eye and that the best we could do was to go to a public hospital, since this could have a complicated and prolonged treatment. I do not think that either the formalities or the manners to deal with this issue were the most appropriate, and because all of this, I felt completely abated, without hope of any improvement or solution.

At this moment I remembered a friend of mine, far younger than me, who had been diagnosed with the same brain tumour behind an eye and who had left us after having suffered a real ordeal.

My perspective was very bad, I needed medical and psychological help, and also guidance about the path to follow, and all of this urgently. I decided to visit two doctors, one of them, a friend of mine who, after I had explained my situation to him, told me that he would give me only one piece of advice: 'in a referral hospital you will be in the hands of the best specialists, do everything they tell you to do, do not ask for second opinions and do not think of changing to another hospital', the second doctor, with whom we have a good relationship, she is our neighbour, and she was a consultant in a referral hospital. She gave me a lot of moral support. She helped to get me seen in a referral hospital, which I did not know how to do, and she has always stood by me, giving me advice and offering me the best support at all times.

In January 2016, I entered the outpatient services of the definitive tertiary referral hospital, being in very bad condition.

I was attended by a doctor who carried out a complete examination and who also reviewed all the documentation that I brought. I felt insecure, worried and afraid, I did not know what the future would hold for me, but I thought that it would not be long and nothing good. I think that the doctor was fully aware of the situation. The interest and the sensitivity of the doctor alleviated me a little.

Different specialists performed many tests on me in order to know the exact disease that I had, which was complex and generated doubts among the different specialists. This uncertainty brought me a lot of anxiety.

\section{Patient's perspective Continued}

In one of the many visits to the doctor he decided to admit me immediately to the coronary unit to remove liquid from the pericardium. To tell the truth I felt very frightened and I came to think that I would not survive.

Some time later it seems that the liquid in the pericardium came back so the medical team decided that I should be immediately admitted to hospital in order to be operated on to remove my pericardium. After the operation I felt more at ease, the operation had gone well and the doctors told me that like this the liquid would not come back any more.

Some adherences of uncertain appearance were found, so they were taken to be examined in pathology, which determined, without any doubt, that I had Erdheim-Chester disease.

Alleviated because I knew what I had but doubtful because it is a rare disease, the doctor reassured me because he said that we would carry out a treatment to fight and overcome it.

The postoperative period went quite well; I felt that my family helped a lot, as well as my doctor and all who attended to me. I started to have hope.

When discharged from hospital, the medication started:

1. Methylprednisolone $500 \mathrm{mg}$ per week for 6 weeks and $250 \mathrm{mg}$ per week for a further 6 weeks.

2. Pegasys 135, every Friday, five boxes (four prefilled pen per box).

Two months later I felt quite better.

After having received five boxes of interferon, it had to be suspended because, despite the fact that the exophthalmia improved, it attacked my skin and produced plenty of big spots on the whole of my body, except for my face. I felt very bad.

I started 2017 with my dermatitis and my exophthalmos improving slowly and progressively, without completely disappearing.

However, the disease attacked me again (1), it caused severe diarrhoea that prevented me from leaving home. At the beginning I stayed on a diet for many days but I did not get

better. I felt bad, insecure and miserable.

In May, they performed a colonoscopy on me, and they immediately prescribed budesonide for 8 weeks and cholestyramine. The chronic diarrhoea improved, and in 2 months I feel much better and I started to feel confident again.

In one of the many visits to the doctor, he found me very unhappy; I told him that I was sleeping badly, and he prescribed Cymbalta; some days later I quickly improved, I felt lively and happy.

They have told me that the disease has attacked my shoulder; I cannot raise my arms above my shoulders. (2) I have to be accompanied in the street because sometimes I have fallen. I have much physical pain (3) but I am happy and hopeful, I have everything: my family, the best doctor and my hospital, so I try not to be far away, I have complete confidence and I have the strength to keep going.

Josefina Casas Pascual

20 February 2018.

in which extrinsic ocular muscles appear enlarged in a spindle shape. ${ }^{142}$ Exophthalmos did not persistently remit until we added interferon alpha to corticosteroids, in accordance with other experiences ${ }^{51} 140143144$ and has remained in remission after stopping them. The patient did not need orbital decompression, often required in ECD. ${ }^{143145146}$ Also, she did not present eyelid 
xanthelasma (figure $1 \mathrm{~A}, \mathrm{~B}$ ), which is frequently associated with exophthalmos in ECD. ${ }^{144}$

The heterogeneous mass seen on the echocardiogram in our patient (figure 5) has been described in other cases. ${ }^{5}{ }^{147}$ In our case, the cardiologist determined that this mass compressed the right ventricle so that it could contribute to the heart tamponade. It has been reported that masses like this cross the atrial wall. ${ }^{148} 149$ Mortality related to cardiovascular involvement in ECD is high. ${ }^{147} 150151$ Our patient survived a menacing recurrent tamponade that definitively remitted with pericardiectomy. Many authors have reported tamponade in ECD. ${ }^{93}$ 152-158 Some consider tamponade as a dangerous rarity within heart involvement in ECD. ${ }^{93}{ }^{154}$ In a case similar to ours, the authors obtained an excellent result with pericardiectomy for severe tamponade. ${ }^{155}$ We agree with them that pericardiectomy has to be considered as a reasonable therapeutic option for menacing recurrent tamponade in ECD.

Should ECD manifestations reappear, we would not give her pegylated interferon because of the bothersome skin reaction she suffered, which has been described in patients receiving pegylated interferon-alpha-2a and interferon-alpha-2b for hepatitis C or B. ${ }^{159-162}$ Since deoxyribonucleic direct sequencing for BRAF was negative, theoretically, there is no option to treat her with the BRAF inhibitors. ${ }^{43}$ We have requested mitogen-activated protein kinase 1 (MAP2K1) and phosphatidylinositol-4,5-bisphosphate 3-kinase catalytic subunit alpha (PIK3CA) mutations detection because there is evidence of successful results treating patients with refractory histiocytosis with MAP2K1 and PIK3CA inhibitors. ${ }^{36}$

Acknowledgements We express our gratitude to: Oscar Andres Cuevas, MD, and to Valentina Mescola, MD, and Pedro Castro, MD, Cirurgia Cardíaca, Hospital de la Santa Creu i Sant Pau, Barcelona, who encountered the diagnostic sign and resolved the most striking outbreak of the disease in the patient. Fernando Rodríguez, MD, Oftalmologia, Hospital de la Santa Creu i Sant Pau, Barcelona, who took care of the ophthalmological manifestations of the patient and provided the ocular images. Maria Pilar Garcia, MD, PhD, Dermatologia, Hospital de la Santa Creu i Sant Pau, Barcelona, who took care of the adverse skin reaction and provided the skin images. Nerea Hernandez, MD, PhD, Medicina Interna, Hospital de la Santa Creu i Sant Pau, Barcelona, internist, who took care of the patient in difficult situations. Miquel Vives Borràs, MD, Cardiologia, Hospital de la Santa Creu i Sant Pau, Barcelona, who took great interest on the peculiarities of the transthoracic Doppler echocardiography. Xavier Torras, MD, Patologia Digestiva, Hospital de la Santa Creu i Sant Pau, Barcelona, who explained to us how to deal with interferon treatment.

Contributors JM has taken care of the patient since she entered in the hospital, has conducted the diagnostic and therapeutic process, with the collaboration of many doctors, and has drafted and carried out this publication with the coauthors and contributors. EG has conducted the radiological diagnosis, has selected and prepared the radiological images for publication, has critically revised the publication as well she has approved it and has agreed on all of its aspects. LL has conducted the histological diagnosis, which has been definitive, has selected and prepared the histological images for publication, has critically revised the publication as well she has approved it and has agreed on all of its aspects. PD has collaborated in

\section{Learning points}

Do not clinically discard Erdheim-Chester disease because of non-existent appendicular bone pain or appendicular bone image involvement; they may be last to appear.

Diabetes insipidus onset in an adult should arouse suspicion of extracranial disease involving the pituitary stalk, of which histiocytoses are prominent.

Extrinsic ocular musculature on orbital magnetic resonance looks thinned and compressed in Erdheim-Chester disease while it appears enlarged in Graves' disease. interpretation of data, has deeply and critically revised the publication as well he has approved and has agreed on all of its aspects.

Funding The authors have not declared a specific grant for this research from any funding agency in the public, commercial or not-for-profit sectors.

Competing interests None declared.

Patient consent Obtained.

Provenance and peer review Not commissioned; externally peer reviewed.

Open access This is an open access article distributed in accordance with the Creative Commons Attribution Non Commercial (CC BY-NC 4.0) license, which permits others to distribute, remix, adapt, build upon this work non-commercially, and license their derivative works on different terms, provided the original work is properly cited and the use is non-commercial. See: http://creativecommons.org/ licenses/by-nc/4.0/

\section{REFERENCES}

1 Emile JF, Abla O, Fraitag S, et al. Revised classification of histiocytoses and neoplasms of the macrophage-dendritic cell lineages. Blood 2016;127:2672-81.

2 Haroche J, Cohen-Aubart F, Rollins BJ, et al. Histiocytoses: emerging neoplasia behind inflammation. Lancet Oncol 2017;18:e113-e125.

3 Munoz J, Janku F, Cohen PR, et al. Erdheim-Chester disease: characteristics and management. Mayo Clin Proc 2014;89:985-96.

4 Abdelfattah AM, Arnaout K, Tabbara IA. Erdheim-Chester disease: a comprehensive review. Anticancer Res 2014:34:3257-61.

5 Mazor RD, Manevich-Mazor M, Shoenfeld Y. Erdheim-Chester Disease: a comprehensive review of the literature. Orphanet J Rare Dis 2013;8:137.

6 Chester W. Über Lipoidgranulomatose. Virchows Archiv für pathologische Anatomie und Physiologie und für klinische Medizin. , 1930:279, 561-602.

7 Stempel JM, Bustamante Alvarez JG, Carpio AM, et al. Erdheim-Chester disease, moving away from the orphan diseases: A case report. Respir Med Case Rep 2017;20:55-8.

8 Atkins HL, Klopper JF, Ansari AN, et al. Lipid (cholesterol) granulomatosis (Chester-Erdheim disease) and congenital megacalices. Clin Nucl Med 1978;3:324-7.

9 Alper MG, Zimmerman LE, Piana FG. Orbital manifestations of Erdheim-Chester disease. Trans Am Ophthalmol Soc 1983;81:64-85.

10 Arnaud L, Hervier B, Néel A, et al. CNS involvement and treatment with interferon- $\alpha$ are independent prognostic factors in Erdheim-Chester disease: a multicenter survival analysis of 53 patients. Blood 2011;117:2778-82.

11 Esmaeli B, Ahmadi A, Tang R, et al. Interferon therapy for orbital infiltration secondary to Erdheim-Chester disease. Am J Ophthalmol 2001:132:945-7.

12 Braiteh F, Boxrud C, Esmaeli B, et al. Successful treatment of Erdheim-Chester disease, a non-Langerhans-cell histiocytosis, with interferon-alpha. Blood 2005; 106:2992-4.

13 Shamburek RD, Brewer HB, Gochuico BR. Erdheim-Chester disease: a rare multisystem histiocytic disorder associated with interstitial lung disease. Am J Med Sci 2001;321:66-75.

14 Jakobson AM, Kreuger A, Hagberg $\mathrm{H}$, et al. Treatment of Langerhans cell histiocytosis with alpha-interferon. Lancet 1987;2:1520-1.

15 Blombery P, Wong SQ, Lade S, et al. Erdheim-Chester disease harboring the BRAF V600E mutation. J Clin Oncol 2012;30:e331-e332.

16 Shapiro P. Ras-MAP kinase signaling pathways and control of cell proliferation: relevance to cancer therapy. Crit Rev Clin Lab Sci 2002;39(4-5):285-330.

17 Badalian-Very G, Vergilio JA, Degar BA, et al. Recurrent BRAF mutations in Langerhans cell histiocytosis. Blood 2010;116:1919-23.

18 Haroche J, Charlotte F, Arnaud L, et al. High prevalence of BRAF V600E mutations in Erdheim-Chester disease but not in other non-Langerhans cell histiocytoses. Blood 2012;120:2700-3.

19 Emile JF, Charlotte F, Amoura Z, et al. BRAF mutations in Erdheim-Chester disease. J Clin Oncol 2013;31:398.

20 Emile JF, Diamond EL, Hélias-Rodzewicz Z, et al. Recurrent RAS and PIK3CA mutations in Erdheim-Chester disease. Blood 2014;124:3016-9.

21 Haroche J, Cohen-Aubart F, Emile JF, et al. Dramatic efficacy of vemurafenib in both multisystemic and refractory Erdheim-Chester disease and Langerhans cell histiocytosis harboring the BRAF V600E mutation. Blood 2013;121:1495-500.

22 Haroche J, Arnaud L, Cohen-Aubart F, et al. Erdheim-Chester disease. Rheum Dis Clin North Am 2013:39:299-311.

23 Haroche J, Cohen-Aubart F, Emile JF, et al. Reproducible and sustained efficacy of targeted therapy with vemurafenib in patients with $\left.B R A F^{(V 600 E}\right)$-mutated ErdheimChester disease. J Clin Oncol 2015;33:411-8.

24 Tzoulis C, Schwarzlmüller T, Gjerde IO, et al. Excellent response of intramedullary Erdheim-Chester disease to vemurafenib: a case report. BMC Res Notes 2015;8:171.

25 Váradi Z, Bánusz R, Csomor J, et al. Effective BRAF inhibitor vemurafenib therapy in a 2-year-old patient with sequentially diagnosed Langerhans cell histiocytosis and Erdheim-Chester disease. Onco Targets Ther 2017;10:521-6. 
26 Borys D, Nystrom L, Song A, et al. Erdheim Chester disease with appendicular skeletal, renal and pleural involvement responding to Zelboraf (BRAF inhibitor) treatment: case report. Skeletal Radiol 2016;45:1397-402.

27 Heisig A, Sörensen J, Zimmermann SY, et al. Vemurafenib in Langerhans cell histiocytosis: report of a pediatric patient and review of the literature. Oncotarget 2018;9:22236-40.

28 Gandolfi L, Adamo S, Pileri A, et al. Multisystemic and multiresistant langerhans cell histiocytosis: a case treated with braf inhibitor. J Natl Compr Canc Netw 2015; 13:715-8.

29 Nordmann TM, Juengling FD, Recher $M$, et al. Trametinib after disease reactivation under dabrafenib in Erdheim-Chester disease with both BRAF and KRAS mutations. Blood 2017;129:879-82.

30 Diamond EL, Durham BH, Haroche J, et al. Diverse and targetable kinase alterations drive histiocytic neoplasms. Cancer Discov 2016;6:154-65.

31 Satoh T, Smith A, Sarde A, et al. B-RAF mutant alleles associated with Langerhans cell histiocytosis, a granulomatous pediatric disease. PLoS One 2012;7:e33891.

32 Brown NA, Furtado LV, Betz BL, et al. High prevalence of somatic MAP2K1 mutations in BRAF V600E-negative Langerhans cell histiocytosis. Blood 2014;124:1655-8.

33 Chakraborty R, Hampton OA, Shen $\mathrm{X}$, et al. Mutually exclusive recurrent somatic mutations in MAP2K1 and BRAF support a central role for ERK activation in LCH pathogenesis. Blood 2014;124:3007-15.

34 Nelson DS, van Halteren A, Quispel WT, et al. MAP2K1 and MAP3K1 mutations in Langerhans cell histiocytosis. Genes Chromosomes Cancer 2015;54:361-8.

35 Cohen Aubart F, Emile JF, Maksud P, et al. Efficacy of the MEK inhibitor cobimetinib for wild-type BRAF Erdheim-Chester disease. Br J Haematol 2018;180.

36 Lee LH, Gasilina A, Roychoudhury J, et al. Real-time genomic profiling of histiocytoses identifies early-kinase domain BRAF alterations while improving treatment outcomes. JCI Insight 2017;2:e89473.

37 Diamond EL, Dagna L, Hyman DM, et al. Consensus guidelines for the diagnosis and clinical management of Erdheim-Chester disease. Blood 2014;124:483-92.

38 Adam Z, Řehák Z, Koukalová R, et al. [PET-CT documented complete remission of Erdheim-Chester disease, lasting more than 4 years from treatment initiation with cladribine]. Vnitr Lek 2014:499:501-11.

39 Myra C, Sloper L, Tighe PJ, et al. Treatment of Erdheim-Chester disease with cladribine: a rational approach. Br J Ophthalmol 2004:88:844-7.

40 Bourke SC, Nicholson AG, Gibson GJ. Erdheim-Chester disease: pulmonary infiltration responding to cyclophosphamide and prednisolone. Thorax 2003;58:1004-5.

41 Boissel N, Wechsler B, Leblond V. Treatment of refractory Erdheim-Chester disease with double autologous hematopoietic stem-cell transplantation. Ann Intern Med 2001;135:844-5.

42 Gaspar N, Boudou P, Haroche J, et al. High-dose chemotherapy followed by autologous hematopoietic stem cell transplantation for adult histiocytic disorders with central nervous system involvement. Haematologica 2006;91:1121-5.

43 Haroche J, Papo M, Cohen-Aubart F, et al. [Erdheim-Chester disease (ECD), an inflammatory myeloid neoplasia]. Presse Med 2017;46:96-106.

44 Durham BH. Molecular characterization of the histiocytoses: Neoplasia of dendritic cells and macrophages. Semin Cell Dev Biol 2018

45 Berres ML, Allen CE, Merad M. Pathological consequence of misguided dendritic cell differentiation in histiocytic diseases. Adv Immunol 2013;120:127-61.

46 Adens A, Landy P, Terriou L, et al. [Usefulness of nuclear medicine in ErdheimChester disease: A Lille experience]. Rev Med Interne 2017;38:235-42.

47 Arnaud L, Malek Z, Archambaud F, et al. 18F-fluorodeoxyglucose-positron emission tomography scanning is more useful in followup than in the initial assessment of patients with Erdheim-Chester disease. Arthritis Rheum 2009;60:3128-38.

48 Moulis G, Sailler L, Bonneville F, et al. Imaging in Erdheim-Chester disease: classic features and new insights. Clin Exp Rheumatol 2014:32:410-4.

49 Haroche J, Arnaud L, Cohen-Aubart F, et al. Erdheim-Chester disease. Curr Rheumatol Rep 2014:16:412.

50 Haroche J, Amoura Z, Wechsler B, et al. [Erdheim-Chester disease]. Presse Med 2007:36:1663-8.

51 Abdellateef EE, Abdelhai AR, Gawish HH, et al. The First reported case of erdheimchester disease in egypt with bilateral exophthalmos, loss of vision, and multi-organ involvement in a young woman. Am J Case Rep 2016;17:360-70.

52 De Abreu MR, Chung CB, Biswal S, et al. Erdheim-Chester disease: MR imaging, anatomic, and histopathologic correlation of orbital involvement. AJNR Am J Neuroradiol 2004;25:627-30.

53 Bahn RS. Graves' Ophthalmopathy. N Engl J Med Overseas Ed 2010;362:726-38.

54 Enzmann DR, Donaldson SS, Kriss JP. Appearance of graves' disease on orbital computed tomography. J Comput Assist Tomogr 1979:3:815-9.

55 Eckstein AK, Plicht M, Lax H, et al. Thyrotropin receptor autoantibodies are independent risk factors for Graves' ophthalmopathy and help to predict severity and outcome of the disease. J Clin Endocrinol Metab 2006;91:3464-70.

56 Watkins LM, Carter KD, Nerad JA. Ocular adnexal lymphoma of the extraocular muscles: case series from the University of lowa and review of the literature. Ophthalmic Plast Reconstr Surg 2011;27:471-6.

57 Bardenstein DS. Ocular adnexal lymphoma: classification, clinical disease, and molecular biology. Ophthalmol Clin North Am 2005;18:187-97.
58 Briscoe D, Safieh C, Ton Y, et al. Characteristics of orbital lymphoma: a clinicopathological study of 26 cases. Int Ophthalmol 2018;38:271-7.

59 Bitik B, Kılıç L, Küçükşahin 0, et al. Retro-orbital granuloma associated with granulomatosis with polyangiitis: a series of nine cases. Rheumatol Int 2015;35:1083-92

60 Rosenbaum JT, Choi D, Wilson DJ, et al. Orbital pseudotumor can be a localized form of granulomatosis with polyangiitis as revealed by gene expression profiling. Exp Mol Pathol 2015:99:271-8.

61 Muller K, Lin JH. Orbital granulomatosis with polyangiitis (Wegener granulomatosis): clinical and pathologic findings. Arch Pathol Lab Med 2014:138:1110-4.

62 Tan LT, Davagnanam I, Isa $\mathrm{H}$, et al. Clinical and imaging features predictive of orbital granulomatosis with polyangiitis and the risk of systemic involvement. Ophthalmology 2014;121:1304-9.

63 Finkielman JD, Lee AS, Hummel AM, et al. ANCA are detectable in nearly all patients with active severe Wegener's granulomatosis. Am J Med 2007;120:643.e9-643.e14.

64 Fernández-Fernández FJ, Sesma P, Rodríguez-Rivas C. Sarcoidosis. N Engl J Med 2008; 358:1403

65 Mavrikakis I, Rootman J. Diverse clinical presentations of orbital sarcoid. Am J Ophthalmol 2007;144:769-75

66 Koyama T, Ueda H, Togashi K, et al. Radiologic manifestations of sarcoidosis in various organs. Radiographics 2004;24:87-104.

67 Demirci H. Idiopathic Orbital Inflammation. Orbital Inflammatory Diseases and Their Differential Diagnosis Essentials in Ophthalmology. Berlin, Heidelberg: Springer, 2015.

68 Szabo B, Szabo I, Crișan D, et al. Idiopathic orbital inflammatory pseudotumor: case report and review of the literature. Rom J Morphol Embryol 2011;52:927-30.

69 Gordon LK. Orbital inflammatory disease: a diagnostic and therapeutic challenge. Eye 2006;20:1196-206

70 Mysore N, Gonçalves FG, Chankowsky J, et al. Adult orbital masses: a pictorial review. Can Assoc Radiol I 2012:63·39-46.

71 Yu WK, Tsai CC, Kao SC, et al. Immunoglobulin G4-related ophthalmic disease. Taiwan J Ophthalmol 2018:8:9-14.

72 Sogabe Y, Ohshima K-ichi, Azumi A, et al. Location and frequency of lesions in patients with IgG4-related ophthalmic diseases. Graefes Arch Clin Exp Ophthalmol 2014;252:531-8.

73 Char DH, Miller T, Kroll S. Orbital metastases: diagnosis and course. Br J Ophthalmol 1997;81:386-90.

74 Green S, Som PM, Lavagnini PG. Bilateral orbital metastases from prostate carcinoma: case presentation and CT findings. AJNR Am J Neuroradiol 1995:16:417-9.

75 Tijl J, Koornneef L, Eijpe A, et al. Metastatic tumors to the orbit-management and prognosis. Graefes Arch Clin Exp Ophthalmol 1992;230:527-30.

76 de Keyser J, Bruyland M, de Greve J, et al. Enophthalmos as a rare manifestation of metastatic orbital involvement. Postgrad Med J 1985;61:149-52.

77 Ashton N, Morgan G. Discrete carcinomatous metastases in the extraocular muscles. Br J Ophthalmol 1974;58:112-7.

78 La Mantia L, Curone M, Rapoport AM, et al. Tolosa-Hunt syndrome: critical literature review based on IHS 2004 criteria. Cephalalgia 2006;26:772-81.

79 Lavaju P, Das H, Malla P, et al. Orbital rhabdomyosarcoma in an adult. Nepal J Ophthalmol 2010;2:64-7.

80 Yazıcı B, Sabur H, Yazıcı Z. Orbital cavitary rhabdomyosarcoma: case report and literature review. Ophthalmic Plast Reconstr Surg 2014;30:e20-2.

81 Ozkurt FE, Ozkurt ZG, Gul A, et al. Managment of orbital complications of sinusitis. Arq Bras Oftalmol 2014:77:293-6.

82 Bedwell J, Bauman NM. Management of pediatric orbital cellulitis and abscess. Curr Opin Otolaryngol Head Neck Surg 2011;19:467-73.

83 Jain S, Goulstine D, Gottlob I. Acute adduction deficit in a 7-week-old infant. Strabismus 2002:10:241-4.

84 Finger PT. Minimally invasive anterior orbitotomy biopsy: finger's aspiration cutter technique (FACT). Eur J Ophthalmol 2012;22:309-15.

85 Deshpande V, Zen Y, Chan JK, et al. Consensus statement on the pathology of IgG4related disease. Mod Pathol 2012;25:1181-92.

86 Murakami Y, Wataya-Kaneda M, Terao M, et al. Peculiar distribution of tumorous xanthomas in an adult case of erdheim-chester disease complicated by atopic dermatitis. Case Rep Dermatol 2011:3:107-12.

87 Asabella AN, Cimmino A, Altini C, et al. (18)F-FDG positron emission tomography/ computed tomography and (99m)Tc-MDP skeletal scintigraphy in a case of ErdheimChester disease. Hell J Nucl Med 2011;14:311-2.

88 Le Goff L, Berros P, Denis D, et al. [Bilateral exophthalmos diabetes insipidus: Erdheim-Chester disease. Clinical and radiological findings]. J Fr Ophtalmol 2002:25:57-61.

89 Sheidow TG, Nicolle DA, Heathcote JG. Erdheim-Chester disease: two cases of orbital involvement. Eye 2000;14:606-12.

90 Veyssier-Belot C, Cacoub P, Caparros-Lefebvre D, et al. Erdheim-Chester disease. Clinical and radiologic characteristics of 59 cases. Medicine 1996;75:157-69.

91 Purgina B, Jaffe R, Monaco SE, et al. Cytomorphology of Erdheim-Chester disease presenting as a retroperitoneal soft tissue lesion. Cytojournal 2011;8:22. 
92 Niu N, Cao X, Cui R. A Unique case of erdheim-chester disease with cervical and lumbosacral nerve involvement: fdg pet/ct finding. Clin Nucl Med 2016;41:881-3.

93 Nakhleh A, Slobodin G, Elias N, et al. Rapid progression to cardiac tamponade in Erdheim-Chester disease despite treatment with interferon alpha. Mod Rheumatol 2016;26:621-4.

94 Lodhi U, Sarmast U, Khan S, et al. Multisystem radiologic manifestations of ErdheimChester Disease. Case Rep Radiol 2016;2016:2670495.

95 Dave AA, Gutschow SE, Walker CM. A Case of Incidentally-diagnosed ErdheimChester Disease. Cureus 2016;8:e781.

96 Bosco J, Allende A, Varikatt W, et al. Does the BRAF ${ }^{(\mathrm{V} 600 \mathrm{E})}$ mutation herald a new treatment era for Erdheim-Chester disease? A case-based review of a rare and difficult to diagnose disorder. Intern Med J 2015;45:348-51.

97 Mazor RD, Manevich-Mazor M, Kesler A, et al. Clinical considerations and key issues in the management of patients with Erdheim-Chester Disease: a seven case series. BMC Med 2014;12:221.

98 Manaka K, Makita N, liri T. Erdheim-Chester disease and pituitary involvement: a unique case and the literature. Endocr J 2014;61:185-94.

99 Akkara Veetil BM, Luthra H. Erdheim-Chester disease. Clin Rheumatol 2011:30:397-8.

100 Mounach A, Nouijai A, Achemlal L, et al. Erdheim-Chester disease: a case report with pulmonary, kidney involvement and bone lesions. Rheumatol Int 2010;30:651-4.

101 Aouba A, Georgin-Lavialle S, Pagnoux C, et al. Rationale and efficacy of interleukin-1 targeting in Erdheim-Chester disease. Blood 2010;116:4070-6.

102 De Filippo M, Ingegnoli A, Carloni A, et al. Erdheim-Chester disease: clinical and radiological findings. Radiol Med 2009;114:1319-29.

103 Matsui K, Nagata Y, Hiraoka M. Radiotherapy for Erdheim-Chester disease. Int J Clin Oncol 2007;12:238-41.

104 Matzumura M, Arias-Stella J, Novak JE. Erdheim-Chester disease: a rare presentation of a rare disease. J Investig Med High Impact Case Rep 2016:4:2324709616663233.

105 Rascón-Ramírez FJ, Avecillas-Chasín JM, Rodríguez-Boto G, et al. [Erdheim-Chester disease, an incredible simulator. Cases reports and review of literature]. Neurocirugia 2016;27:296-303.

106 Loeffler AG, Memoli VA. Myocardial involvement in Erdheim-Chester disease. Arch Pathol Lab Med 2004;128:682-5.

107 Lim J, Kim KH, Suh KJ, et al. A Unique Case of Erdheim-Chester Disease with axial skeleton, lymph node, and bone marrow involvement. Cancer Res Treat 2016:48:415-21

108 García-Gómez FJ, Cambil-Molina T, Ríos-Martín JJ, et al. Bone scintigraphy as cornerstone in the diagnosis of Erdheim-Chester disease. Rev Esp Med Nucl Imagen Mol 2016:35:193-6.

109 Drier A, Haroche J, Savatovsky J, et al. Cerebral, facial, and orbital involvement in Erdheim-Chester disease: CT and MR imaging findings. Radiology 2010;255:586-94.

110 Gupta A, Aman K, Al-Babtain M, et al. Multisystem Erdheim-Chester disease; a unique presentation with liver and axial skeletal involvement. Br J Haematol 2007;138:280

111 Dion E, Graef C, Miquel A, et al. Bone involvement in Erdheim-Chester disease: imaging findings including periostitis and partial epiphyseal involvement. Radiology 2006:238:632-9.

112 Ivan D, Neto A, Lemos L, et al. Erdheim-Chester disease: a unique presentation with liver involvement and vertebral osteolytic lesions. Arch Pathol Lab Med 2003;127:e337-9.

113 Kenn W, Stäbler A, Zachoval R, et al. Erdheim-Chester disease: a case report and literature overview. Eur Radiol 1999;9:153-8.

114 Franzius C, Sciuk J, Bremer C, et al. Determination of extent and activity with radionuclide imaging in Erdheim-Chester disease. Clin Nucl Med 1999;24:252-5.

115 Bancroft LW, Berquist TH. Erdheim-Chester disease: radiographic findings in five patients. Skeletal Radiol 1998:27:127-32.

116 Bulycheva EN, Baykov VV, Zaraǐskiĩ MI, et al. Rare form of erdheim-chester disease presenting with isolated central skeletal lesions treated with a combination of alfainterferon and zoledronic Acid. Case Rep Hematol 2015;2015:876752.

117 Poiroux L, Paycha F, Polivka M, et al. Efficacy of zoledronic acid in Erdheim-Chester disease: A case report. Joint Bone Spine 2016:83:573-5.

118 Srikulmontree T, Massey HD, Roberts WN. Treatment of skeletal Erdheim-Chester disease with zoledronic acid: case report and proposed mechanisms of action. Rheumatol Int 2007;27:303-7

119 Courtillot C, Laugier Robiolle S, Cohen Aubart F, et al. Endocrine manifestations in a monocentric cohort of 64 patients with Erdheim-Chester Disease. J Clin Endocrinol Metab 2016:101:305-13.

120 Kim MS, Kim CH, Choi SJ, et al. Erdheim-chester disease. Ann Dermatol 2010;22:439-43.

121 Adam Z, Sprláková A, Rehák Z, et al. [Partial regression of CNS lesions of ErdheimChester disease after treatment with 2-chlorodeoxadenosine and their full remission following treatment with lenalidomide]. Klin Onkol 2011;24:367-81.

122 Adam Z, Balsíková K, Krejcí M, et al. [Central diabetes insipidus in adult patients-the first sign of Langerhans cell histiocytosis and Erdheim-Chester disease. Three case studies and literature review]. Vnitr Lek 2010;56:138-48.
123 Adam Z, Balsíková K, Pour L, et al. [Diabetes insipidus followed, after 4 years, with dysarthria and mild right-sided hemiparesis-the first clinical signs of ErdheimChester disease. Description and depiction of a case with a review of information on the disease]. Vnitr Lek 2009:55:1173-88.

124 Wright RA, Hermann RC, Parisi JE. Neurological manifestations of Erdheim-Chester disease. J Neurol Neurosurg Psychiatry 1999:66:72-5.

125 Vital C, Bioulac-Sage P, Tison F, et al. Brain stem infiltration by mixed Langerhans cell histiocytosis and Chester-Erdheim disease: more than just an isolated case? Clin Exp Pathol 1999;47:71-6.

126 van der Lee I, Slee PH, Elbers JR. A patient with diabetes insipidus and periorbital swellings; Erdheim-Chester disease. Neth J Med 1999;55:76-9.

127 Fukazawa T, Tsukishima E, Sasaki H, et al. Erdheim-Chester disease and slowly progressive cerebellar dysfunction. J Neurol Neurosurg Psychiatry 1995;58:238-40.

128 Tien R, Kucharczyk J, Newton TH, et al. MR of diabetes insipidus in a patient with Erdheim-Chester disease: case report. AJNR Am J Neuroradiol 1990;11:1267-70.

129 Rice CM, Hall CA, McCoubrie P, et al. Erdheim-Chester disease: 25-year history with early CNS involvement. BMJ Case Rep 2016;2016.

130 Ding H, Li Y, Ruan C, et al. Chinese Erdheim-Chester disease: clinical-pathology-PET/ CT updates. Endocrinol Diabetes Metab Case Rep 2015;2015:150055.

131 Campochiaro C, Tomelleri A, Cavalli G, et al. Erdheim-Chester disease. Eur J Intern Med 2015:26:223-9.

132 Caparros-Lefebvre D, Pruvo JP, Rémy M, et al. Neuroradiologic aspects of ChesterErdheim disease. AJNR Am J Neuroradiol 1995;16:735-40.

133 Evidente VG, Adler CH, Giannini C, et al. Erdheim-Chester disease with extensive intraaxial brain stem lesions presenting as a progressive cerebellar syndrome. Mov Disord 1998;13:576-81

134 Tritos NA, Weinrib S, Kaye TB. Endocrine manifestations of Erdheim-Chester disease (a distinct form of histiocytosis). J Intern Med 1998;244:529-35.

135 Ono K, Oshiro M, Uemura K, et al. Erdheim-Chester disease: a case report with immunohistochemical and biochemical examination. Hum Pathol 1996;27:91-5

136 Cavalli G, Guglielmi B, Berti A, et al. The multifaceted clinical presentations and manifestations of Erdheim-Chester disease: comprehensive review of the literature and of 10 new cases. Ann Rheum Dis 2013;72:1691-5.

137 Adawi M, Bisharat B, Bowirrat A. Erdheim-Chester disease (ECD): Case report, clinical and basic investigations, and review of literature. Medicine 2016;95:e5167.

138 Cives M, Simone V, Rizzo FM, et al. Erdheim-Chester disease: a systematic review. Crit Rev Oncol Hematol 2015;95:1-11.

139 Perić P, Antić B, Knezević-Usaj S, et al. Successful treatment with cladribine of Erdheim-Chester disease with orbital and central nervous system involvement developing after treatment of Langerhans cell histiocytosis. Vojnosanit Pregl 2016:73:83-7.

140 Quintana-Quezada RA, Postalian A, Yeh YC. Erdheim-Chester Disease presenting with intractable exophthalmos and bone lesions. Am J Med Sci 2016:352:e7.

141 Martinez R. Erdheim-Chester disease: MR of intraaxial and extraaxial brain stem lesions. AJNR Am J Neuroradiol 1995;16:1787-90.

142 Müller-Forell W, Kahaly GJ. Neuroimaging of Graves' orbitopathy. Best Pract Res Clin Endocrinol Metab 2012:26:259-71.

143 Nicolazzi MA, Carnicelli A, Fuorlo M, et al. Cardiovascular involvement in erdheimchester disease: a case report and review of the literature. Medicine 2015:94:e1365.

144 Haroche J, Amoura Z, Trad SG, et al. Variability in the efficacy of interferon-alpha in Erdheim-Chester disease by patient and site of involvement: results in eight patients. Arthritis Rheum 2006:54:3330-6.

145 Manousaridis K, Casper J, Schittkowski MP, et al. [Erdheim-Chester disease of the orbit with compressive optic neuropathy]. Ophthalmologe 2010;107:266-9.

146 Hoffmann EM, Müller-Forell W, Pitz S, et al. Erdheim-Chester disease: a case report. Graefes Arch Clin Exp Ophthalmol 2004:242:803-7.

147 Haroche J, Cluzel P, Toledano D, et al. Images in cardiovascular medicine. Cardiac involvement in Erdheim-Chester disease: magnetic resonance and computed tomographic scan imaging in a monocentric series of 37 patients. Circulation 2009:119:e597-8.

148 Berti A, Ferrarini M, Ferrero E, et al. Cardiovascular manifestations of ErdheimChester disease. Clin Exp Rheumatol 2015;33:S155-S63.

149 Tan IB, Padhy AK, Thng CH, et al. Intensely hypermetabolic extra-axial brainstem tumor in Erdheim-Chester disease. Clin Nucl Med 2009;34:604-7.

150 Graziani G, Podestà MA, Cucchiari D, et al. Erdheim-Chester disease: from palliative care to targeted treatment. Clin Kidney J 2014;7:339-43.

151 Haroche J, Amoura Z, Dion E, et al. Cardiovascular involvement, an overlooked feature of Erdheim-Chester disease: report of 6 new cases and a literature review. Medicine 2004:83:371-92.

152 Chasseur P, Kyriakopoulou M, Vokaer B, et al. A cytologic diagnosis of BRAF ${ }^{\mathrm{V} 600 \mathrm{E}}$ Erdheim-Chester disease on pericardial fluid. Acta Clin Belg 2017:72:1-3.

153 Vega J, Santamarina M. [Sirolimus and prednisone for the treatment of ErdheimChester disease with cardiac involvement: Report of one case]. Rev Med Chil 2016; 144:394-400.

154 Mishra AK, Mani S, George AA, et al. Recurrent pericardial effusion and tamponade in a patient with Erdheim-Chester disease (ECD). BMJ Case Rep 2015;2015:bcr2015212483. 
155 George OK, Subhendu MS. Recurrent and rapidly occurring pericardial tamponade in Erdheim Chester disease. Indian Heart J 2012;64:103-5.

156 Vega J, Cisternas M, Bergoeing M, et al. [Erdhei-Chester disease: report of one case]. Rev Med Chil 2011:139:1054-9.

157 Gupta A, Kelly B, McGuigan JE. Erdheim-Chester disease with prominent pericardial involvement: clinical, radiologic, and histologic findings. Am J Med Sci 2002:324:96-100.

158 André $\mathrm{M}$, Delèvaux I, de Fraissinette B, et al. Two enlarged kidneys: a manifestation of Erdheim-Chester disease. Am J Nephrol 2001;21:315-7.
159 Tang DM, Ward L. Rash from hepatitis C treatment. Cleve Clin J Med 2011;78:472-4.

160 Kawada K, Maeda N, Kobayashi S, et al. Injection site with generalized rash caused by pegylated interferon alpha 2a injection. Dermatology 2006;212:82-3.

161 Milkiewicz P, Yim C, Pache I, et al. Diffuse skin reaction in patient with hepatitis B, treated with two different formulations of pegylated interferon. Can I Gastroenterol 2005;19:677-8

162 Meller S, Erhardt A, Auci A, et al. [Drug-induced exanthema caused by pegylated interferon-alpha 2b]. Hautarzt 2003;54:992-3.

Copyright 2018 BMJ Publishing Group. All rights reserved. For permission to reuse any of this content visit

http://group.bmj.com/group/rights-licensing/permissions.

BMJ Case Report Fellows may re-use this article for personal use and teaching without any further permission.

Become a Fellow of BMJ Case Reports today and you can:

- Submit as many cases as you like

- Enjoy fast sympathetic peer review and rapid publication of accepted articles

- Access all the published articles

- Re-use any of the published material for personal use and teaching without further permission

For information on Institutional Fellowships contact consortiasales@bmjgroup.com

Visit casereports.bmj.com for more articles like this and to become a Fellow 